PHYSICAL REVIEW A 75, 019905(E) (2007)

\title{
Publisher's Note: Threshold effect in the energy loss of slow protons and deuterons channeled in Au crystals [Phys. Rev. A 75, 010901 (2007)]
}

E. A. Figueroa, E. D. Cantero, J. C. Eckardt, G. H. Lantschner, J. E. Valdés, and N. R. Arista

(Received 23 January 2007; published 29 January 2007)

DOI: 10.1103/PhysRevA.75.019905

PACS number(s): 61.85.+p, 99.10.Fg

This paper was published online on 22 January 2007 with a typographical error in Fig. 2. The vertical axis label in Fig. 2 should read as $\Delta E / \Delta x(\mathrm{eV} / \AA)$. The figure has been corrected as of 25 January 2007. The figure is correct in the printed version of the journal. 